\title{
Computation (Abacus) Aspects of the Sahasralingam
}

\author{
Jayabrata Mukherjee \\ Murugeshpallya, \\ Bangalore-17, Karnataka, India
}

\author{
Deepak Bhattacharya, PhD \\ C/o Sri Radha Krishna, \\ Kedar Gouri Road, \\ Bhubaneswar-751002, India.
}

\begin{abstract}
India claims deep heritage in ancient sciences and specially in Mathematics \& Astronomy - which means computation. Evidence based works not noted (archaeology platform). Sahasralingam (million indicator) is a artifact of indo archaeology. One devise from Bhubaneswar is studied from computation aspects. Has 1020 indentures which transpires as magic number. Sets of various types; Fibonacci; Pi; Permits continuous computations viz., calculus, algebra, discreet math in imperative and declarative languages; offers semantics; embedment; steganography \& VLSI type; lattices of various orders; types \& axis; symmetry with versatility and an extraordinary level of mathematical maturity is reported from the first time. 1020 posits also as unique \& novel testing platform number.
\end{abstract}

\section{Keywords}

Sahasralingam; Computation; Sanatan Vigyan; Indian Ancient Sciences; Vrihanka-Pingala anka; Indian archaeology Fibonacci; Pi; Hindu Mathematics; Hindu Astronomy.

\section{INTRODUCTION}

During the last decade, Bhattacharya has been have reporting various aspects of evidence based history of sciences in indoarchaeology [see Ref.1,2,6,9,10,11,12,14,15], including one artifact that depicts a helio-centric concept[1]. Author-1 has been studying the possible applied meaning of the Sahasralinga since 20yrs before present. In the Journal Of The Asiatic Society [2] he has presented its (i) pan India archaeological similars (ii) historical and cultural connotations (iii) discussed its possible date - pre-dating Aryabhatta-I by a wide margin (iv) select aspects of the associated archaeoastronomy, and finally posited the Sahasralingam (iv) as a gnomon \pillar devise i.e., a secular instrument of yore to evidence in-space natural phenomenons. And, natural phenomenons provide unique solutions and inspiration for computational purposes. This treaties discusses the computation applications vis-à-vis such pillar (i.e., the Sahasralingam) as if it be a scientific device of yore that was used to conduct such \& related studies. Herein, the Sahasralingam has been imagined as an abacus; numbers from 1-to-1020 have imputed and the results are presented as tentative findings. The deductions posit as having unique and novel applications in computation with versatility. Such type of study and report has not been done pre to this communication.

The historical cum cultural identity of the candidate archaeology's locale is Kalinga (cleaver \& intelligent) [3], Utkala (excellent) and Kosala (capable), which have an enviable heritage in high rise construction (intact array); architecture [4, 5]; compass \& maritime engineering [6-7]; inspirational designs [8]; positional astronomy [9,10] and archaeoastronomy [11,12] continuously from c.6th A.D [13], onwards to the world heritage monument 'Konarak' (super fine resonance, c. 14th A.D.). Logically, the local society also has numerous types and units of weights and measures. Kathi (stick) is one such. This communication may be read along with Advanced Science Letters [14] \& Journal of The Asiatic Society (Ref-2).

\section{MATERIAL \& METHODS}

Fig-1a is the devise pictographically recorded at about 14-30 IST (Indian standard time) on datum Dec., solstice. The upper portion is known as rudra bhag (solar region). It shows the Brahmasutra (cosmic maxim). The mechanical aspects are given in Fig.1b. The device has 20 rows, each having 51 lingas i.e., 51 x $20=1020$ lingas. The term 'linga' implies 'indicator' (see Ref. No.1). Authors have been observing and recording this gnomon since 1993. A tome of data has been generated. In order to transport the reader to the site a pictographical route is adopted levitated by heuristic cum pedagogic method of narration to enliven the embedded citra katha (hieroglyphics). Time \& period based round the clock field repeat observations is performed in-situ at site ranging over a decade. The overall study ranged around two decades. 


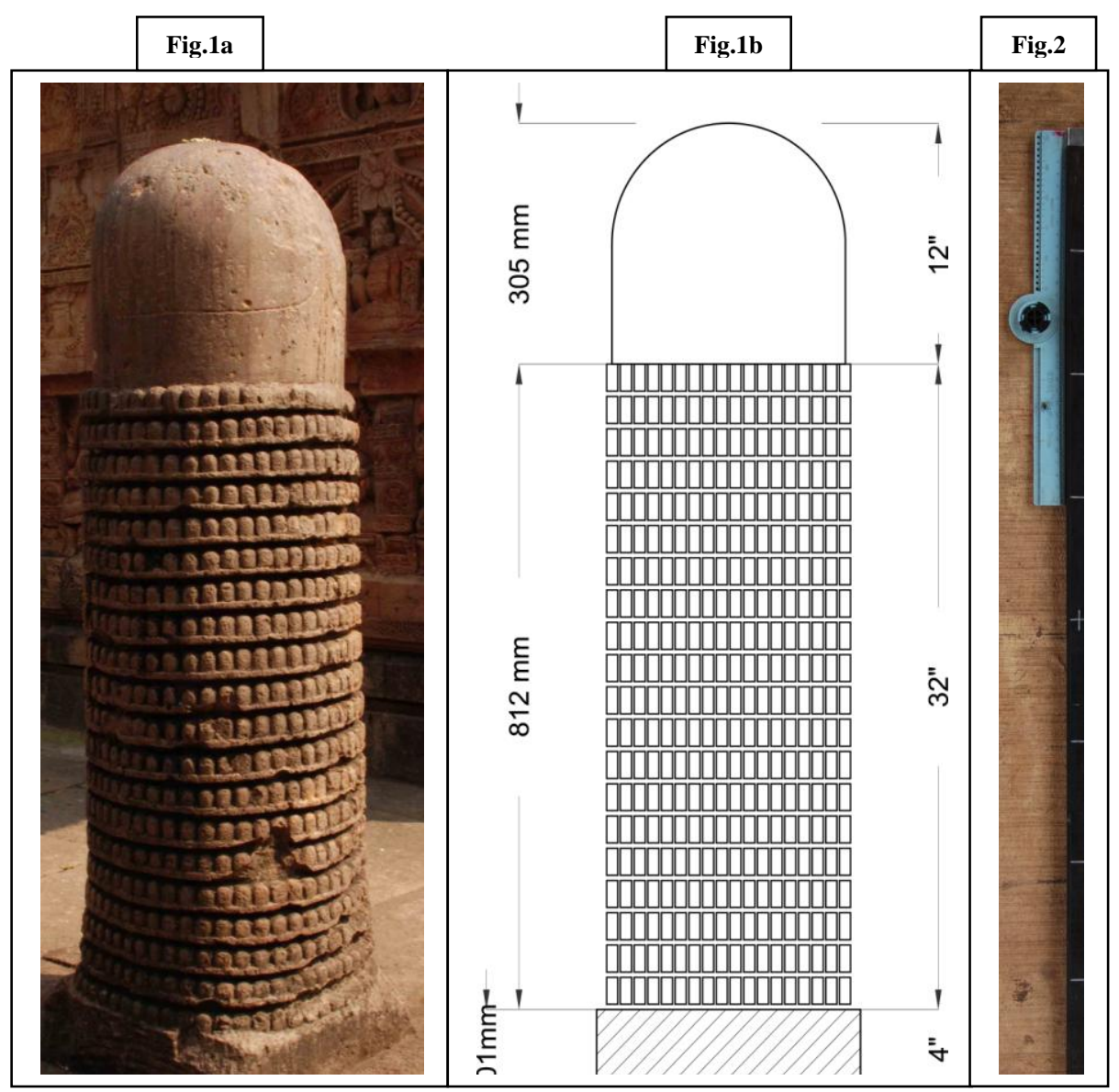

Saharasralinga is a pillar device. It is an ancient gnomon. F-1a, Prarasurameswar temple, c. 650 A.D., Bhubaneswar, India. F-1b is mechanical aspects. F-2 is the dwi-kathi (two). It is a traditional scale. I K = 16 Inches. It is used at Bhubaneswar.

\section{FINDINGS}

Pan India every such devise presents similar aspects and yet not identical. Each represents a gamut of aspects of the ancient schools of sanatan vedic vigyan (perennial plural sciences). The Kathi is one such instrument of measure for length (Fig-2), with standard graduations, having extensive use. Bhattacharya \& Naik $[15,16]$ have earlier used this. D. Mitra [17] the Director General of The Archaeological Survey of India had earlier opined that Orissan sthapatis (master craftsmen) have kathis of various measures. We have selected a kathi that is $=16$ inches for its suits our model (also used at Sri Lingaraj temple). Although the gnomon's top is a dome the actual height remains the same or $48 \div 16=3 \mathrm{kathi}$ as per traditional scale $(3 \mathrm{k}=48$ inches $)$.

Interestingly, $3600 \div 70=510.51$ indicators (lingas) are noted on the gnomon describing the azimuth at a separation of 70 at 20 celestial and or terrestrial levels represented by the 20 rings on the Sahasralinga which is a cylindrical device, the sides of which makes it a parallelogram (Fig-1b). Noteworthy is that there is no report thus far of an erect cylinder having equally spaced 20 rings indentured equally 51 times $(20 \times 51$ $=1020)$ on which diurnal rotation of light $\&$ shadow can be observed along with diurnal swings, seasonal oscillation, respectively, and also having an versatile abacus (enrolled). We note that light \& shadow generation, duration and angle of the play are very different on a geometrically indentured cylinder from that of any other geometric form. All play outs are also accountable numerically and/or graphically (even jointly) using the 1020 indentures, continuously. Such play off being specific to location on ground (geographic), location of sun/astrals yields the universal time constant (UTC) in relation to time in space, repeating with precession. Thus the Sahasralinga attracts the present mind as a possible scientific device of the past minds (complex \& versatile).

\section{FIBONACCI IN ARCHAEOLOGY}

In the Orient, mathematics alike any other constituents of the sciences was reduced to sutras (maxims). Even theorems and results are rendered in verse for convenience of compression, memorization, stack, store and specially for reproduction with economy \& élan. The infinite series of $1.6: 1$ (progression) existed in c.700 A.D., being noted in Chanda Sutra (metrical maxims) in the works of Vrihanka (great numerical series) with umbilical connection to Sri Pingala (the Golden) who's upper date is considered as c.2nd B.C., which are erroneously categorised as 'prosody' (laws of accent). Although distanced by a millennia the two works can be presented conjointly and is also intonated as pingala vrihanka (great golden series). Either are also rendered in Sanskrit lingua via Devanagari script. The term 'pingala' is a metaphor as much as is 'vrihanka'. And, the great minds of the past in the Orient (India in particular) have always been re-anointed with (secular) metaphors that best represents their contribution/cases. Such a series in now known as the 'Golden Ratio'. Indulgently connectable historical phonetics based on stemmatics makes a good case for Sri Pingala as the genetic author and Sri Vrihanka as the series developer. In the Occident named after and attributed to Leonardo Fibonacci (c.1202 A.D.) of Pisa, Italy, the modern mathematical sequence wherein each subsequent number is the sum of the previous two is known as 'Fibonacci series' in 
Anglo Saxon and in all other European lingua. Observed backwards it works out also as a constant difference of $1.6: 1$ ('golden ratio') between any two contiguous numbers of the series. Such ratio has also been shown variedly in various natural manifestations and phenomena and hence is considered as reckon magic [18]. In modern engineering it yields durability, stability; anti-shock propagation and stress bearing ability, etc. Now, pingala vrihanka has unique applications in computer hard ware and more in VLSI, embedment, steganography (major deflections with minor switching), and in modeling weather, catastrophes, etc., which all appears not to have been explored.

The man made sanatan (hydespas) heritage in load structure engineering of Sri Parasuramaeswar (candidate Saharsralingam's site) was completed by c. 650 A.D. The royal patron Sri Madhavaraja - II (c.610-65A.D., [19] was the mahasamanta (great ally) of Maharajdhiraj Sasanka (emperor) who died inte-state around c.642-44 A.D., after killing emperor Pulakesin -II and also emperor
Harsavardhan's younger brother (Rajyavardhan). Hence, Madhavaraja his Mahasamanta performed the Asvamedha yagna (live horse sacrifice); took on the title of 'sakalakalingadhipati' (lord of the whole of Kalinga). Obviously, he was the centre of attraction and the peerless cynosure of the then brilliant minds \& of the able bodies, pan India (the then). In celebrations thereof he built the shrine of Parasuramaeswar as his victory monument. Irrigation engineers indicate that river Prachi (Orient) drained the domain. Historians in context indicate the phrase 'prachi upataka savyata' (Orient valley civilization). Archaeologists are reporting new sites along the either banks of this erstwhile river, that terminates near UNESCO-world heritage site of Konarak (super fine resonance). Therefore, we make a nascent attempt to trace Fibonacci series in our candidate archaeology. Fibonacci is attractive in advance computational methods.

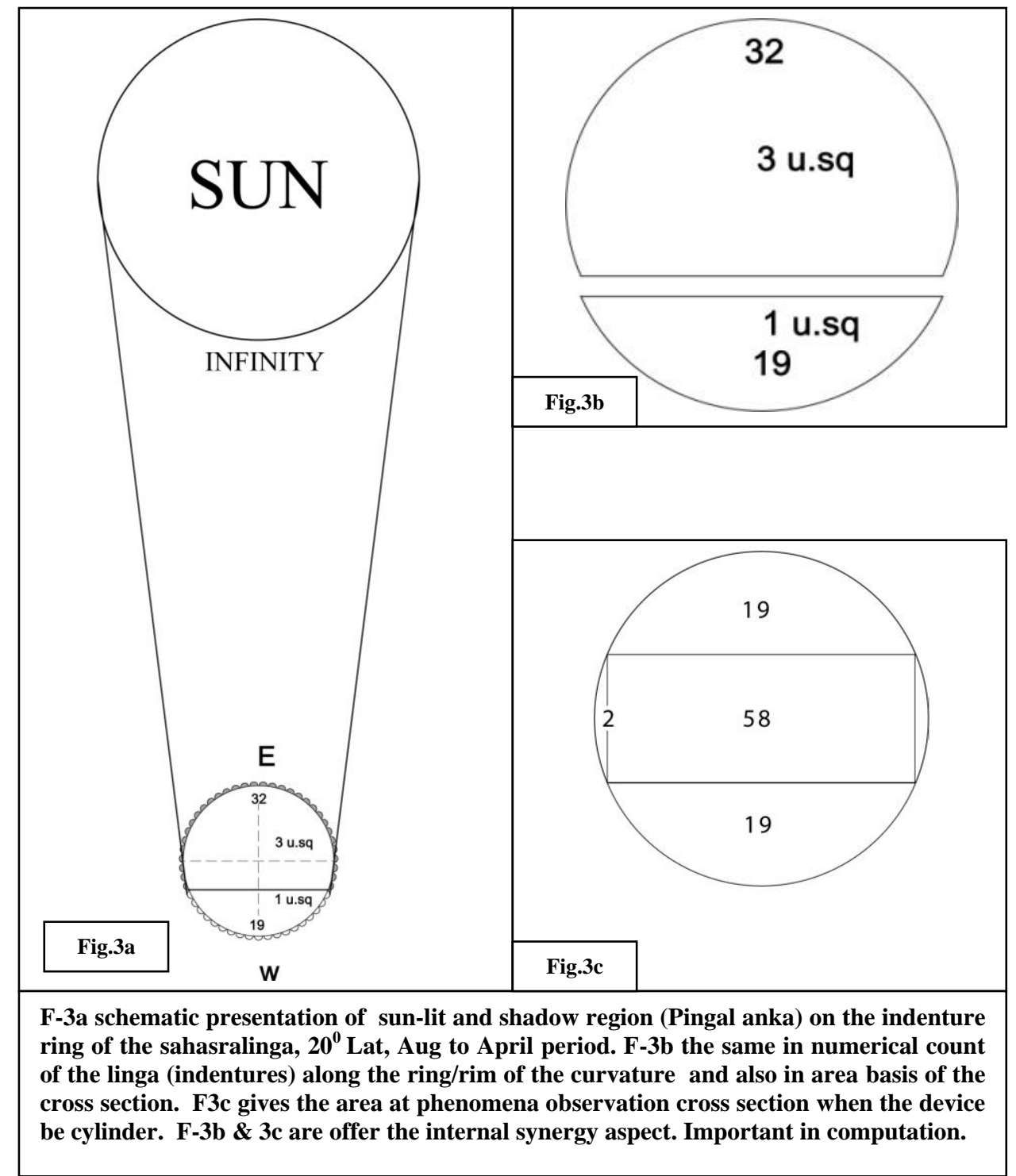

Vis-à-vis Fibonacci what is mother nature telling us ? What did the ancient mind do to reflect such hearing (sanatan vigyaan) ? Therefore, a few Fibonacci aspects are discussed in shadow rotation on the sahasralingam the ancient pillar device (not on the ground). Such an exercise using an hitherto unexplained yet ubiquitous free standing archaeological member has not been attempted pre to us. The term Sahasralingam means 100,000 indications. In Kashi 
(Benaras, Sri Vishwanath gallillane) it is called Koti-Linga $(1000,000$ indicator).

From 3rd week of May to 3rd week of July i.e., approximately for 90 days period (colloquially chaturmasa grishma $\mathrm{N}$ hemisphere summer) no shadow of the rudra bhag (dome; Fig-1a) is cast on the top ring of the abacus during the noon pass period. During the rest of the year the sun-shade rotation remains uninterrupted. It is noted that on the top ring there is always a coupled shadow-light regions as alike umbrapenumbra (Fig-3a). Table -1 gives the long period observations. The measure of the shadow region is of 19 lingas and the measure of the lighted region is of the measure 32 lingas $=51$ lingas. During the period mid Aug-to-May (9 months) such coupled form of the light-\&-shade is noted also during the noon pass apart all the other diurnal hours (whole day phenomenon) i.e., anksik chaya in sunya (partial shadow in spacelat an elevation) and not on bhumi (ground). Partial shadows in space are umbras and partial lighted regions are penumbras. Thus the Sahasralingam generates an umbrapenumbra couple on the top ring. In other words, the rudra bhag acts as an opaque body and projects a anksik chaya. The architecture of such chaya in sunya is different from its chaya on bhumi at the same moment. The Sahasralingam device fractionates the azimuth@70 (3600 $\div 51)$. Shadows are not hard ware. The Sahasralingam is. Therefore, the angle of the shadow of the sun (lightlenergy) is readable at a separation of 70 on the top ring via chaya in sunya. If the atypical architecture of an abacus enrolled cylinder is not used, then all these are not evidenced. It is a device for evidence based studies (not observation based). Here an angle of the spinlincidence is noted (incident angle of the input signal), etc., which all are important for arriving at variable results with perfect repeatability using a common hardware. And, numer 7 is unique \& novel (vital). And, 7 is conspicuous by absence in modern computing

Table :1

\begin{tabular}{|c|c|c|c|c|c|}
\hline \multirow{2}{*}{ Date } & \multirow{2}{*}{ Time - UTC } & \multirow{2}{*}{$\begin{array}{c}\text { Period } \\
\text { Of the day }\end{array}$} & & \multicolumn{3}{|c|}{ Top rings } \\
\cline { 4 - 6 } & & Lighted & Shadow & Total \\
\hline $21 / 03$ & $04-30$ & Fore noon & 32 & 19 & 51 \\
\hline $03 / 05$ & $03-00$ & - do- & 32 & 19 & Do \\
\hline $21 / 06$ & $02-45$ & -do- & 32 & 19 & Do \\
\hline $10 / 08$ & $02-55$ & -do- & 32 & 19 & Do \\
\hline $21 / 09$ & $08-15$ & After noon & 32 & 19 & Do \\
\hline $21 / 12$ & $08-00$ & -do- & 32 & 19 & \\
\hline
\end{tabular}

NOTE : $1: 1$ denotes, recorded whence shadow Length on ground $=$ height of sahasralingam. Such $1: 1$ phenomena occurs because the sun describes an angle of $45^{\circ}$ to base (hypotenuse of a right angled triangle). At such instant the length of the shadow $=$ to height of the gnomon (3kathi). We have selected such moments because it a definite point in space (T-3) to prove that the Pingala anka (golden ratio alais Fibonacci) is a year round phenomena and is evidence based.

Ratio $19: 32$ is a Fibonacci couple, (i) numerically and (ii) geometrically i.e., area wise (Fig-3a). Such coupled phenomena rotates diurnally and oscillates seasonally (poly core processors with oscillation within the main !). Fig. $3 b$ gives the arc and the volume wise coverage (engineering platform CAD being used). In Fig. 3c the lower unit has been transposed into the upper field to describe an rectangle at centre. Using CAD the areas of respective regions of a circular section have been indicated. The umbra region is 1 unit 2 also extending over 19 lingas, while the penumbra region is 1.6 times that of the shadow region, is of 3 unit 2 and has 32 lingas. There are 2 mini regions on the either side of the rectangle. The rectangle region is 9 times that of any such side mini regions. The rectangle region is 3 times $(1: 3)$ that of the region described by the 18 shadowed lingas. Such $1: 3$ \& 1:9 ratios are numerously met with in kalingiya built archaeology (collateral info). In signal power fractionation, signal transport and above all in transformation such ratios great flexibility with assurance.

This $19 \& 32$ (umbra-penumbra couple i.e. equivalent of flip $\&$ flop) can be assumed as groups and laid out as follows :

19-32 [ 4 ] $28-64$ [8] 56 - 128 [16] 112 - 256 [32] 224 $512 \ldots \ldots \ldots$ wherein $4,8,16,32 \ldots .$. represent the intersection, which spatially are constant yet are exponential in work done ability.
It is a case of set a $\bar{U}$ B set ( set theory comes into play). And, the sets are numerous and varied.

1020 divided by $19=53$ points of intersections ( 53 repetitions of equal order) and or 52 stages or levels or planes or fields of numbers. Each having a serial. These be one set of lattices.

1020 divided by $32=32$ of intersections ( 32 repetitions of equal order) AND or 31 stages or levels or planes or fields of numbers. Each having a serial. These be another set of lattices.

Thus there are $20 \times 51=1020$ numbers which yields numerous lattices (x axis).

Further $53 \times 31=1643$ yield a cascade comprised of the above 2 lattices (y axis).

Diagonal lattices are also noted (not shown). These be token examples.

Off the 1020 (deemed circuits), 10-101-1010 least binary command and posit as a dynamic ping line in testing. 1020 units enable synapses in millions - in all the form of the lattices in every desired plane (fractals apart). Values may indicate power cum the volume of the function, etc., and or cache! 


\section{CORELATIONING WITH ARYA BHATTA}

Let us now briefly touch computational aspects relating to large domains (time \& space) as is given to us by Arya Bhatta [20]. Sri Arya Bhatta (c.476 A.D.), in chapter Ganita pada 4.1 (calculation steps) assumes a circle of a diameter of 20,000 units. We too can work out a similar number viz., $4680 \times 4+1020=19740$. In Gitika Pada -3.5 (steps in verse ) he mentions the periods for each yuga (epoch), the gross total making a Mahayuga (great epoch) of 43,20,000year units, further mentioning a ratio of $1: 2: 3: 4$ between the 4 yugas. We too can work out near similar numbers and ratios on our abacus, (Table-1)

1020 is comprised of the 1 st three alpha-numerical series viz., $0,1 \& 2$. And 1020 is exactly divisible by $2,3,4,5 \& 6$ and leaves a reminder of 0.7 when divided by 7 . So is the case with 510 (correlate with A.K.Bag's commentary [22]. Our device predates Bhatta (Ref-2).

Table :2

\begin{tabular}{|c|c|c|c|c|c|c|}
\hline $\mathbf{1}$ & \multicolumn{2}{|c|}{ I } & II & III & IV & Remarks \\
\hline & \multicolumn{3}{|c|}{ Ratios } & \multirow{2}{*}{$\begin{array}{l}\mathbf{1 0 2 0} \div \\
\text { Ratio } \\
\text { Minimum } \\
\text { multiple with } \\
85 \text { as } \\
\text { common } \\
\text { factor. }\end{array}$} & \multirow{2}{*}{$\begin{array}{c}\text { Ratio- } \\
\text { between } \\
\text { Contiguous } \\
\text { Numbers = } \\
\text { Geometrically } \\
\text { progressing } \\
\text { fractions; }\end{array}$} & \multirow{4}{*}{$\begin{array}{c}\text { We } \\
\text { Arrive at } \mathbf{8 5} \text {. } \\
\text { Note }: 85 \text { can be also } \\
\text { articulated as } 8 \& 5=13 \\
\text { which can be articulated } \\
\text { as } 1+3 \text {, thereby } 85 \text { yields } \\
1,3,4,5 \& 8 \text {; See } \\
\text { Graph }-2 \& \text { Table- } 2\end{array}$} \\
\hline 2 & \multicolumn{3}{|c|}{$\begin{array}{c}1020 \times 1020 \times 4=41,61,600 \\
\text { Aryabhatta's Mahayuga = 43,20,000. } \\
\text { (Bhatta's yugabda ratio } \\
\text { using } 1020 \text { as a determinant) }\end{array}$} & & & \\
\hline 3 & $4161600 \div 1=$ & $\begin{array}{c}4161600 \text { or } \\
(1020 \times 1020 \times 4)\end{array}$ & $1020 \div 4$ & $\begin{array}{c}=255 \\
\text { (or } 85 \times 3 \text { ) }\end{array}$ & $\begin{array}{c}1 \\
(255)\end{array}$ & \\
\hline 4 & $4161600 \div 2=$ & $\begin{array}{c}2080800 \text { or } \\
(1020 \times 1020 \times 2)\end{array}$ & $1020 \div 3$ & $\begin{array}{c}=340 \\
\text { (or } 85 \times 4)\end{array}$ & $\begin{array}{c}1.3 \\
(340 \div 240)\end{array}$ & \\
\hline 5 & $4161600 \div 3=$ & $\begin{array}{c}1387200 \text { or } \\
(1020 \times 1020 \times \\
1.3)\end{array}$ & $1020 \div 2$ & $\begin{array}{c}=510 \\
\text { (or } 85 \times 6 \text { ) }\end{array}$ & $\begin{array}{c}1 \frac{1}{2} \\
(510 \div 340)\end{array}$ & $\begin{array}{l}\text { Kutuhala of Ratios } \\
\text { (whole range of }\end{array}$ \\
\hline 6 & $4161600 \div 4=$ & $\begin{array}{c}1040400 \text { or } \\
(1020 \times 1020)\end{array}$ & $1020 \div 1$ & $\begin{array}{c}=1020 \\
\text { (or } 85 \times 12 \text { ) }\end{array}$ & $\begin{array}{c}2 \\
(1020 \div 510)\end{array}$ & $\begin{array}{c}\text { Theta }[\theta] \text { operators can } \\
\text { be Derived ) }\end{array}$ \\
\hline 7 & $1: 2: 3: 4$ & $4: 1.3: 1$ & $4: 3: 2: 1$ & $3: 4: 6: 12$ & $1: 1.3: 1.5: 2$ & $1 ; 1.3 ; 1.5 ; 2 ; 3 ; 4 ; 6 ; 12$ \\
\hline
\end{tabular}

Arya Bhatta mentions the number 43,20,000 [22]. It relates to time in space (shifting) in relation to earth (relative fixed point). In Table - I the nearest is $4161600(1020 \times 155$ being less by $1,58,400)$. This shows how VLSI technique is embedded in our model.

Arya Bhatta in ganita pada-4.2, indicates the numer 85 as the one that leaves an reminder of $5,4 \& 1$ when divided by 8,9 $\& 7$, respectively. This is kutaka (fractal) as well as 1 st degree indeterminate concept (algebra). This is an identical case.
Further, 17 which is perfectly indivisible number if be divided by 5,2,3,\& 9 leaves an remainder of $4,5,6 \& 8$, respectively. And, 85 is 5 times of 17 which is $1 / 3$ of 51 . The term 'ganita pada' means calculus (mathematical steps).

Herein below the cylinder of the Sahasralingam is layed out as a graph. Numers being imputed serially ( 1 - to - 1020) from reader's left to right. They present select embedded abacus matters. Are unique and hitherto unknown. Table -I presents a unique array of computation tools. 
Graph 1 : Marks the position 1 (start), 17, $34 \& 51$, which is perfectly divisible by 17 (either are uneven numbers). 510 is the mid way number. $510 \div 162=\pi(3 \cdot 148)$. On the hypotenuse it is mid way of 324 which in turn makes the highest value integer couple with 1020 to make a Pi of least reminder. That, 1-162-324-1020 make a diagonal on our rectangle and a geometric statement. Gray boxes (51-104-408) mark the values of a natural Panava (slim waist member). These be loops of various types.

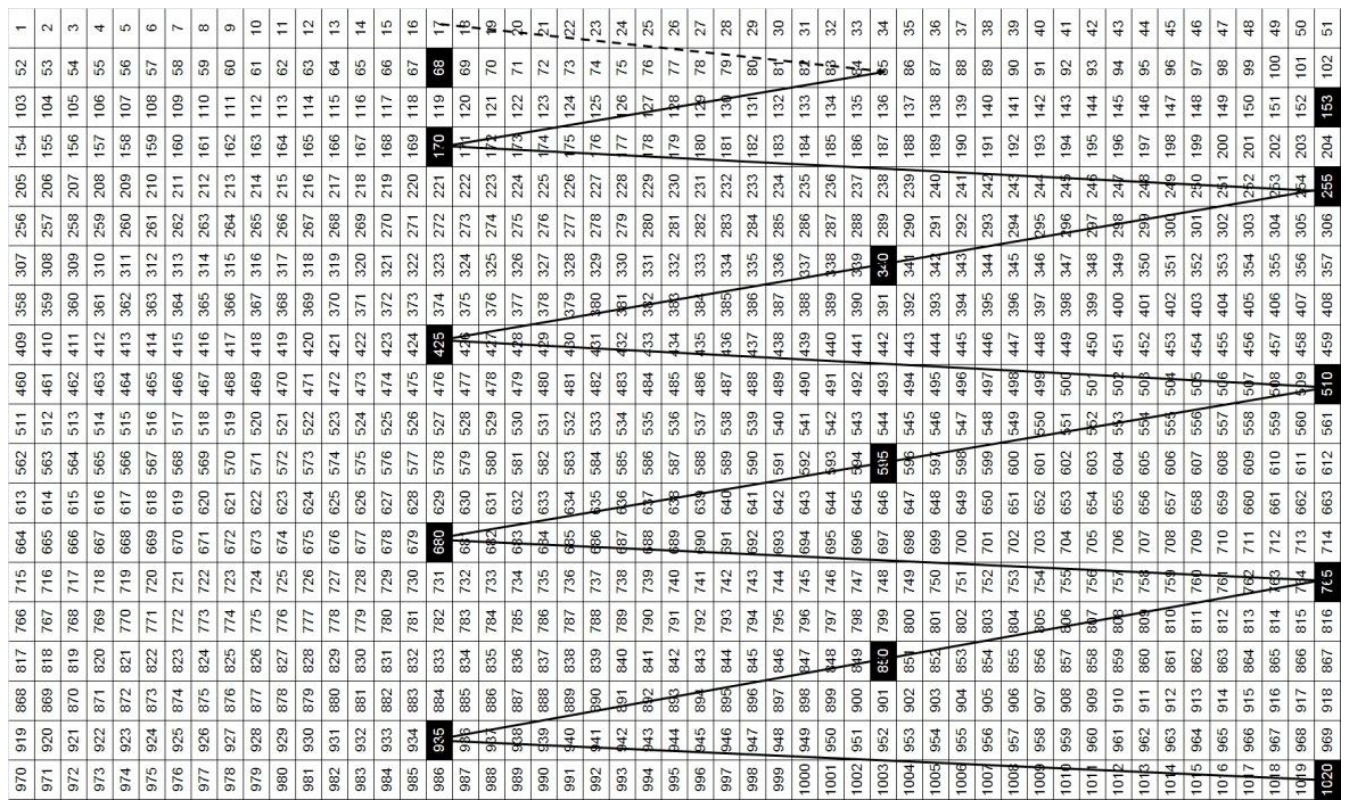

\section{Graph :2}

Graph: 2 : In continuation of the katha (story) as in G-1, the katha in G-2 starts with 17, 5 times of which is 85 (number mentioned by AryaBhatta); thereafter multiples of 85 (from $85 \times 1$ to $85 \times 12$ ) have been highlighted - which in turn shows the left hand and the right hand rule in geometric form.

Graph-2 shows 51 is perfectly divisible by 17 five times of which is 85 and their uniqueness. We have then marked (multiples of 85), 85, 170, 255, 340, 425, 510, 595, 680, 785, 850,935 and 1020 . This is a geometrical series of 17 ranging from $17 \times 5-$ to $-17 \times 60$. On the graph we have connected the series. The length dimension in the ascending order is shorter (r-to-l) than that of the descending order (l-to-r). Our abacus has an (embedded) right hand rule and an left hand rule (among others). $17 \& 85$ are its unique core numer pair.

If the values of the G-1 diagonal be altered then the lattice in G-2 take a paradigm shift; permitting games in number play. G-1 \& G-2 is a case of symmetry between numbers and geometry $=$ dynamic mathematics $=$ lot of applied use potential. Furthermore, while the user application compatibility for large values is loudly apparent, the application of this graph (geom. form) in the domain of nano scale applications are hidden even from the opportunistic eye.
We may also conjecture the following: That from 1-to-510 is a hemisphere of a globe. The other being from 510-to-1020. This may be liked to dual core/ 2 identically laid out systems having exponentially differing processing capabilities. Alphabets can also be used to represent large operation initiators, steps, result and or to zip, as did Arya Bhatta (geetika pada).

\section{PI ASPECTS}

Arya Bhatta has opined that $\mathrm{Pi}$ is asana (inconclusive). Modern mathematicians have opined it to be 'irrational'. Herein are discussed a few aspects of the Pi as are embedded in the sahasralingam 1020 value model. In Graph -1 the hypothetical diagonal that connects $1 ; 162 ; 324$ \& 1020 all have a nexus with the infinite Pi value series that has only 3 digit repeating reminder (shortest), with an exponential progression between each of the remaining numbers (e.g. 148, ..., ...). Such a series on a graph makes a straight line indicating it to be the shortest even on a geom., and the relevance of our abacus vis-à-vis Pi analysis. 324 posits as the golden Pi factor for the magical 1020 (see Graph-1 \& Table 2). Further, the numerical that construct the Pi 3.148 can be generated as $4-1=3 ; 4-3=1 ; 3+1=4 ; 3+1+4=8$ (no other numer is

needed).

Table :3 : Few select pairs yielding identical infinity series of the Pi.

\begin{tabular}{|c|c|c|c|}
\hline Series & Integer pairs & The Pi value repitap series (new) & Notable Issues \\
\hline 1 & $1020 \div 324$ & $3.1481481481481481481481481481481 \ldots \ldots$ & Denominator 148 series is geometric \\
\hline -do- & $765 \div 243$ & Do - & 148 is also the shortest repitap \\
\hline -do- & $510 \div 162$ & $-\quad$ Do - & Divisor is a multiple of 85 \\
\hline -do- & $255 \div 81$ & Do - & Divider is a multiple of 27 (uneven). \\
\hline -do- & $85 \div 27$ & Do - & \\
\hline \multicolumn{4}{|c|}{ The multiples of 27 are peerless Pi values. And, $\sqrt{27}=3^{2} \times 3$. } \\
\hline Series & \multicolumn{3}{|c|}{ We also get the known series. Series -2 as token example for compare with Series-1. } \\
\hline 2 & $22 \div 7$ & $3.142857 \quad 142857 \quad 142857 \quad 142857142857 \ldots \ldots$ & Upto $6^{\text {th }}$ decimal point \\
\hline
\end{tabular}




\begin{tabular}{|c|c|c|c|}
\hline -do- & $44 \div 14$ & - Do - & Divider is a multiple of the uneven 7. \\
\hline -do- & $88 \div 28$ & - Do - & Divisor is a multiple of 22 \\
\hline -do- & $176 \div 56$ & - Do - & \\
\hline -do- & $352 \div 112$ & - Do - & - Do - \\
\hline -do- & $704 \div \div 224$ & We can also say, series Pi-1 = Series Pi-2 ! \\
\hline \multicolumn{2}{|r|}{}
\end{tabular}

NOTE : Integer pairs are limited to within the field values of our abacus (1-to-1020).

Now, the integer pairs span varying domains of operations (switching). They are yet another set of number with a reverse flow! And, there are 12 such pairs. The repitab series of 3.148 \& 3.142857 are repeated 6 times with the numerical field of 1-to-1020. The pair be among the smallest which portend excellent conservation of the applied energy across any potential and also the best binary enabled. From Srinivas through to present time Indian mathematicians have not indicate any such item [23]. $\mathrm{Pi}$ is attractive in advance computational methods. This section be concurrently read with Ref. No. 14.

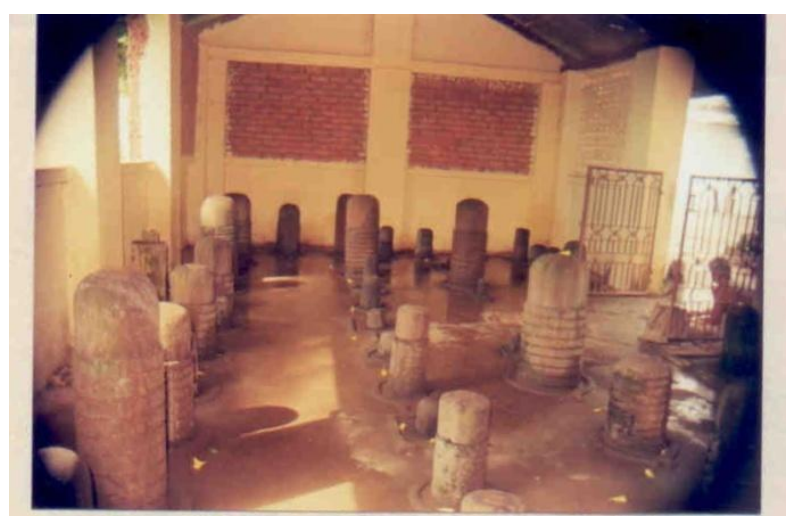

Fig.4: Jajpur town, Odisa, Sri Viraja Devi Temple complex, adjacent museum (north)

\section{HISTORY \& HERITAGE ASPECTS}

As alike the term sahasralingam, astotara too is a sanskrit (self gelling) phone. It means 108. It too is a magic number, and a sacred one. The largest of the astotara is housed inside the shrine of Sri Kalahasti (right bank of the $\mathrm{N}$ flowing river Suvarna), Dist. Chitoor, Andhra Pradesh. The largest possible gathering of sahasralinga variants is in a field museum at Sri Viraja Ksetra (right bank of rive Brahmani), Jajpur town, Dist. Jajpur, Odisha (Fig.4) - Odisa Govt effort. Such collection permits comparative studies. Only Sri Kalahasti member is out of bounds for non-Hindus. Isolated mono members (sahasralingamlastotara) liter the right banks of various stream and rivers. As compared to this. The left bank was the choice of the Buddhists of the Hinayana-Mahayana orders (hence bereft). Thus, they have been considered as bamamargis (left hand rule people). Almost all Hindu heritage sites in the Deccan and its coastal, as at Ekamra (Bhubaneswar) have various editions of the sahasralingam. Many a member pre-date Greece. These artifacts be mankind's tangible heritage. Each offer a magic number with unique-\&-novel lattices (often yielding identical results). The embedded katha come down as intangible heritage. The sahasralinga (plural) is a pan-indo member as much is siddhanta sciences \& practices. The Hindu reveres it and care much. A huge tome of magic numbers are awaiting, beckoning the enterprising minds.

\section{DISCUSSION}

Our inspiration has been ancient Indian archaeology; Indian history of sciences related literature and the question as to 'what does mother nature do vis-à-vis computations'? Non reveled to us nor indicated remotely anything contained herein. The sahasralinga and all its variants are scientific devices. Are secular. Are versatile. They were not made on one fine day, neither by any super fine genius. They represent the cumulative knowledge via cumulative effort ranging a long historical period. They are also portable (migration enabled); are mostly items of field archaeology and hence are accessible by the non-Hindus. Our understanding about them is nascent and rudimentary. Hence, our study is not exhaustive. If we discount our modern learning of geo-spatial sciences; multi-disciplinary fields; training in occidental methods of enquiry and research modeling, we then stand dumb \& mute, marveling and wandering, clueless, abysmally.

The phone pair 'sanatan vigyan' means 'perennial sciences'. And the sahasralingam is a device of such sciences. It is not a religion related item. Religion has been apportioned onto it due existential crisis and to fend from the idiot, the evil \& the vandal. The term lingam means (indicationlindicator; see Ref. No. 2) and whereas, in popular psyche it denotes Siva (Hindu supreme god head) which is a synonym of joyltruth. For the past minds in this part of the world, symmetry full computation was truth-joy (Siva-Siva). Therefore, the author duo bow and prostrates before the sahasralinga and utter "Om Namah Sivaya" (hail the truth). No revisionist agenda.

\section{CONCLUSION}

We have only presented select aspects. Regarding the abacus there are a lot many embedded maters that needs fuzzy logic for decipherment. The ancient mind has applied steganographic modus. They speak to the beholder in her/his lingua using numerical script. It encrypt an amazing range with versatility. Apart numbers and geoms, offers semantics i.e., denotes a range of ideas-from the popular to the highly technical (all embedded). The system is loaded with junction values and positions. Each junction number posits as a logic gate enabling Boolean function/s in various lattices. That and those lattices seem to be operable in various angles of the planes. Permits, continuous computations viz., calculus, 
algebra, discreet math in imperative and declarative languages. The final number $1020 \mathrm{can}$ be represented as dash-dot-dash dash-dot dot. And, yet, log is not the sole (as in occidental abacuses). The whole being over layed with sets of various orders, functions and potential. Is resplendent with robust \& vital mathematics. Symmetry \& versatility are the hall marks. An extraordinary level of mathematical maturity is observed. In fact, what not of mathematics ? An enticing beehive of loops \& pings posits it also as a unique and novel 'testing platform'. Conclusion is pectoris to pen. We invite the enabled minds.

\section{ACKNOWLEDGMENT}

Authors are indebted to many for this long period study, including photographer Mr. K.N. Raj, CAD specialists M/s Rhythm Engineers (deputed numerous engineers and trainee engineers who all helped with drawings for 10 long years) and to altruistic helpers. These presents are to our fore-fathers and esteemed gurukool (collegiums) i.e., Siddhanta Bari (House of Siddanta). Study commenced in 1993 and we are happy to indicate that it is inconclusive. Special Thanks to Dr. Dwiti Krishna Panigrahi for assisting with field trips, physically helping climbing and photography \& continuous support.

\section{REFERENCES}

[1] Bhattacharya, Deepak., \& P. C. Naik, "A Report On A Heliocentric Planetary System In Indian Archaeology”, Journal of The Asiatic Society, Vol. LIII. No.1, 2011, pp.19-26.

[2] Bhattacharya, Deepak., The Brahmasutra On The Siva Lingas And The Orion's Path : Theoretical And Astronomical Study, Journal of The Asiatic Society, VOL.LIV (2), 2012, pp.9-24.

[3] Apte's, V. S., The Practical Sanskrit English Dictionary, Ed. by Gode \& Karve, Prasad Prakashan, Poona, 1957, Part - II, p. 547.

[4] Ganguly, M. M., Orissa and Her RemainsAncient and Medieval (District- Puri), Calcutta, 1912. (Ganguly was Civil Engineer by profession)

[5] Bose, N. K., Cannons of Orissan Architechture, Cosmo Publication, $1^{\text {st }}$ Ed., New Delhi, 1920.

[6] Bhattacharya, Deepak., \& P. C. Naik, "An Ancient Mariner's Compass : Select Discussion”, International Journal of Maritime Studies, VOL.22. No.2, Oct.-2008, pp.221-242. [Versatile Compass for Mariner's Use. Heritage]. hrcak.srce.hr/file/49124

[7] Bhattacharya Deepak \& P.C. Naik, Maritime Heritage of Odisha (New Inland Dock),Utkal Historical Research Journal, VOL. XXI, 2008, Utkal Uni., pp. 61-72.

[8] International Space Development Conference ISDC; http://www.isdc2009.org

NASA, http://www.nss.org/settlement/nasa/Contest/Results/2009 /index.html - See also Times of India, 13-05-2009, and other National News Papers. OR Browse the term pair of "ODISA; Gajaraj".
[9] Bhattacharya Deepak, "Positional Astronomy and Nataraja [c. 650AD]", Commemoration Volume in Respect of B. P. Sinha, 'Purabharati' : Studies in Early Historical Archaeology and Buddhism, Vol. 1, Sharada Publishing, Delhi, 2006, pp. 219 - 222.

[10] Deepak Bhattacharya, P. C. Naik, J. P. Mohanto., 2016, A Possible Ancient City of Stars : TARAKA (India), Odisha Historical Research Journal, ISSN No. 04747269, Vol. LV, No.1 \& 2, 2016, pp. 87-96.

[11] Bhattacharya, Deepak., \& $\quad$ P. C. Naik, Archaeoastronomy at Bhubaneswar, Indian Journal of History of Science, Indian National Science Academy, Vol.41, No.1, Mar.2006, pp. 53-75.

[12] Bhattacharya, Deepak., \& P. C. Naik, Archaeoastronomy of Nataraj, Indian Journal of Hist. of Science, Indian National Science Academy, Vol.43.3, Sep.2008, pp.411-423.

[13] Panigrahi, K.C., History of Orissa, 2nd Ed., Kitab Mahal, Cuttack, 1982

[14] Bhattacharya, Deepak., Is Hindu Astro-Mathematical Traditions Traceable in Indo Archaeology ?, Advanced Science Letters, Vol. 22, No. 2, 2016, pp.319-326.

[15] Bhattacharya, Deepak., \& P. C. Naik, "Archaeometry : A Glimps into History of Ancient Indian Engineering Science", Journal of the Institution of Engineers, India, VOL. No. $89,17^{\text {th }}$ Oct.2008, pp.9-15. Our Kathi (Fig-2) has been got from Sardar Maharana (Lead Carpenter) of Sri Lingaraj Temple. This scale is used in the making of the famous annual chariots.

[16] Deepak Bhattacharya \& P. C. Naik, "AstroNavigational Aspects of the Bhumi Anla", Indian Journal of Hist. of Science, Indian National Science Academy, Vol.43.1, 2008, pp.83-92.

[17] Mitra, D. Konarak, Hand Book, A S I, New Delhi, 1985.

[18] Rath, S.K. \& Naik, P.C., Fibonacci Structure In Conch Shell, Current Science, No.4, (2005), pp. 555-57.

[19] Panda S. K., Political \& Cultural History of Orissa, New Age Int. 1999, Delhi, p.194.

[20] Rao, S. B., Ed., "Aryabhatta $-\mathrm{I}$ and His Astronomy", Rashtriya Sanskrit Vidyapeetha, Tirupati, 2003, p.35.

[21] Bag, A.K., Mathematics in Ancient and Medieval India, (Full Book) Chowkhamba Oriental Series, Varanasi, 1976.

[22] Bhaskaracharya-II, Aryabhatiyam of 17; Ud.3. See also : Bhaskaracharya, Bija Gañita, Odisa State Museum -iron stylus engraved (hoary) Palm Leaf Manuscript, No. G.1. See also Indian Journal of Hist. of Science, Indian National Science Academy, Vol.43.1, 2008, pp. 101-08.

[23] R. C. Gupta, "Book Review”, Indian Journal of History of Science, Indian National Science Academy, Vol. 41, No.1, Mar, pp.123-29.2006. 